\title{
Impact of Number of Positive Lymph Nodes and Lymph Node Ratio on Survival of Women with Node-Positive Breast Cancer
}

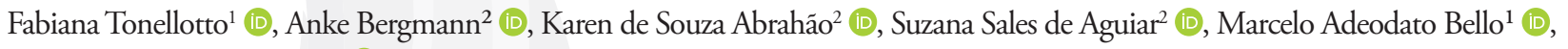
Luiz Claudio Santos Thuler ${ }^{2}$ (i)

${ }^{1}$ Department of Surgical Oncology, Mastology Service, Hospital do Câncer III, Instituto Nacional de Câncer (INCA), Rio de Janeiro, Brasil ${ }^{2}$ Department of Clinical Research, Research Center, Instituto Nacional de Câncer (INCA), Rio de Janeiro, Brasil

\section{ABSTRACT}

Objective: This study aimed to evaluate the association of axillary lymph node ratio (LNR) and number of positive lymph nodes (pN) with the risk of breast cancer recurrence and death.

Materials and Methods: A retrospective cohort study of node-positive stage II and III breast cancer patients diagnosed and treated between 2008 and 2009 at the Brazilian National Cancer Institute (INCA), Brazil. Overall and disease-free survival curves for number of positive lymph nodes (pN) and lymph node ratio (LNR) risk groups were constructed using the Kaplan-Meier method and compared by the log-rank test. Multivariate analysis was performed using stepwise forward Cox regression models.

Results: In total, 628 women with node-positive breast cancer were included. Most patients (69.5\%) had advanced clinical stage tumors ( $\geq$ IIB). The median follow-up was 58 months (range: 3-92 months). The adjusted recurrence hazard of pN2 and pN3 patients was 2.47 ( $95 \%$ Confidence Interval [CI] 1.72-3.56) and $2.42(1.62-3.60)$, respectively, compared to $\mathrm{pN} 1$ patients $(\mathrm{p}<0.001)$, while the hazard of intermediate $(0.21-0.65)$ and high-risk ( $>0.65)$ LNR was $2.11(1.49-3.00)$ and 3.19 (2.12-4.80), respectively, compared to low-risk LNR $(\leq 0.20)$ patients $(\mathrm{p}<0.001)$. On the other hand, the hazard of death of $\mathrm{pN} 2$ and $\mathrm{pN} 3$ patients was $2.17(1.42-3.30)$ and 2.41 (1.53-3.78), respectively $(\mathrm{p}<0.001)$, and the hazard of intermediate $(0.21-0.65)$ and high-risk $(>0.65)$ LNR patients was $1.70(1.13-2.56)$ and $2.74(1.75-4.28)$, respectively $(\mathrm{p} \leq 0.001)$.

Conclusion: Higher $\mathrm{pN}$ and LNR were associated with shorter disease-free survival and overall survival times.

Keywords: Breast cancer, disease-free survival, overall survival, lymph node ratio, positive lymph nodes

Cite this article as: Tonellotto F, Bergmann A, de Souza Abrahão K, de Aguiar SS, Bello MA, Thuler LCS. Impact of Number of Positive Lymph Nodes and Lymph Node Ratio on Survival of Women with Node-Positive Breast Cancer. Eur J Breast Health 2019; 15(2): 76-84.

\section{Introduction}

Breast cancer accounts for $23 \%$ of all cancers in women worldwide (1). The incidence is rising in developing countries, and in Brazil, 59.700 new breast cancer cases are expected in 2019 according to the Brazilian National Cancer Institute (INCA) (2).

In 1882, William Halsted introduced the radical mastectomy as the standard treatment for breast cancer and since then, axillary lymph node dissection (ALND) has been adopted as a common surgical technique for nodal assessment (3). The management of breast cancer has evolved significantly ever since and sentinel lymph node biopsy (SLNB) has been introduced into the routine clinical practice. SLNB has lower morbidity compared with classic ALND $(4,5)$. In a clinical trial held by The American College of Surgeons Oncology Group Z0011 (ACOSOG Z0011), clinically node-negative patients with T1-T2 tumors and patients with 1-2 positive sentinel lymph nodes (SLNs) who were treated with breast conserving-surgery and breast radiotherapy were submitted to SLNB alone or SLNB plus ALND and no differences were observed in the 10-year overall survival (OS) and disease-free survival (DFS) rates $(4,5)$.

Lymph node involvement has long been recognized as an important prognostic factor in breast cancer. The presence of positive axillary lymph nodes is a predictor of increased risk of local and distant recurrence, directly affecting mortality. The association between lymph node involvement and survival has been previously demonstrated (6-8) and it has been shown that overall survival rates are up to $40 \%$ lower in node-positive patients compared with node-negative ones (8). 
The number of lymph nodes involved $(\mathrm{pN})$ has traditionally been used for post-surgical staging of breast cancer. In addition, the lymph node ratio (LNR), defined as the ratio of positive lymph nodes to the total number of lymph nodes removed, has emerged as a prognostic factor in a growing number of studies. A higher LNR is associated with a worse prognosis in breast cancer $(3,9)$.

Other unfavorable prognostic factors include extracapsular invasion and perinodal fat infiltration. Several studies have shown that extracapsular extension is an important unfavorable prognostic factor in many types of cancer, including breast cancer $(1,6,7,10,11)$. The relevance of extracapsular invasion and perinodal fat infiltration as a risk factor for local and distant recurrence in women with breast cancer has been demonstrated by several studies $(1,11)$. In addition, some studies have suggested an association between other indicators of the extent of axillary disease such as the size of nodal metastasis and prognosis $(7,12,13)$.

This study aimed to evaluate the effect of $\mathrm{pN}$ and LNR on overall survival and disease-free survival of women with node-positive breast cancer.

\section{Material and Methods}

This is a retrospective cohort study of node-positive breast cancer patients (ICD-10, C50) diagnosed and treated between 2008 and 2009 in a reference cancer center in Brazil. The study was approved by the INCA Research Ethics Committee under protocol number 128/11.

Patients 18 years of age and older presenting with clinical stage II and III breast cancer were included. As per institutional routine, all patients underwent mastectomy or segmental resection + ALND (Berg levels I, II or I, II and III) with or without previous axillary lymph node biopsy.

Patients without information on clinical stage (two patients) and number of positive lymph nodes (four patients) were excluded.

Patients were identified from the Hospital Cancer Registry (RHC). Data were collected directly from physical and electronic hospital records and medical charts. The following sociodemographic variables were evaluated: age ( $<50$ years or $\geq 50$ years), ethnicity (Caucasian or others), education ( $<8$ years or $\geq 8$ years of education), and marital status (with or without partner). The tumor variables evaluated were: clinical stage ( $<$ IIB or $\geq$ IIB), histological type (non-special type invasive carcinoma or others), Elston histological grade (1-2: low grade; 3: high grade), estrogen and progesterone receptor status (positive or negative), and Her-2 overexpression (positive or negative).

These axillary specimens were carefully examined by pathologists with a large experience in breast cancer. The pathology process was standardized by the use of a combination of entire submission, fat clearing, visualization and palpation, in order to increase the detection of lymph nodes. Axillary lymph nodes were examined for the total number of lymph nodes removed, number of positive lymph nodes $(\mathrm{pN})$, and lymph node ratio (LNR.) The number of positive lymph nodes on histopathological examination was stratified according to the staging system of the American Joint Committee on Cancer and The Union for International Cancer Control (AJCC/UICC) into pN1 (1-3 positive lymph nodes), pN2 (4-9 positive lymph nodes), and $\mathrm{pN} 3$ ( $\geq 10$ positive lymph nodes) $(14,15)$. Patients were grouped into low- $(\mathrm{LNR} \leq 0.20)$, intermediate- (LNR 0.21-0.65), and high-risk
(LNR>0.65) LNR groups based on the staging classification proposed by Vinh-Hung et al. (10). In addition, perinodal fat invasion and/or extracapsular invasion (yes/no) were also evaluated.

Surgical treatment consisted of mastectomy or segmental resection + ALND. Data on the following adjuvant treatments were also evaluated: radiotherapy in the residual breast tissue or chest wall (yes/no), chemotherapy (yes/no), hormone therapy (yes/no), and trastuzumab (yes/no).

Survivor patients were followed-up at least 5 years. Disease-free survival (DFS) and overall survival (OS) were endpoints of the study. Locoregional recurrence was defined as a pathologically proven recurrence in the ipsilateral chest wall, supraclavicular and infraclavicular regions, axilla, and internal mammary area. Distant metastasis was defined as recurrence at any site other than those above described and was confirmed by imaging studies and histopathological evidence when necessary. DFS was defined as the time from the date of surgery until local or distant relapse was detected (event) or the last followup date. OS was defined as the interval between initial diagnosis and death (event) or the last follow-up date.

Descriptive statistics were used for the calculation of measures of central tendency and dispersion for continuous variables and frequency distributions for categorical variables. Differences in median were compared by Mann-Whitney test. Overall and disease-free survival curves for different $\mathrm{pN}$ and LNR risk groups were constructed using the Kaplan-Meier method and compared by the log-rank test at $\mathrm{p}<0.05$. Multivariate analysis was performed using stepwise forward Cox regression models, and all variables associated with the outcome variables at $\mathrm{p}<0.20$ on univariate analysis were included in multivariate models. A p value $<0.05$ was considered statistically significant in the final model. All analyses were performed using Statistical Package for the Social Sciences version 21.0.0 (IBM Corp,.; Armonk, NY, USA).

\section{Results}

During the study period, 628 women underwent surgery for invasive breast cancer with axillary lymph node involvement and no distant disease. The median age was 54 years (range: 23-91 years), most women were Caucasian (55\%), single (54\%), and had completed eight or more years of education (57\%) (Table 1).

Most patients had advanced clinical stage tumors ( $\geq \mathrm{IIB})$; the predominant histological subtype was high-grade (48\%) invasive carcinoma of no special type (87\%). Estrogen and progesterone receptors were positive in $76 \%$ and $66 \%$ of cases, respectively, and Her- 2 overexpression was observed in $24 \%$ of patients (Table 1 ).

The median number of lymph nodes removed per patient was 19 (range: $6-77$; median=18 in the neoadjuvant chemotherapy group; 20 in the adjuvant chemotherapy group; and 19 in the no chemotherapy group; $\mathrm{p}=0.998)$. Nearly all women $(98 \%)$ had 10 or more lymph nodes removed, and the median number of positive lymph nodes was four (range: 1-77). Based on the AJCC/UICC staging system, 304 patients were classified as pN1 (48\%), $186(30 \%)$ as $\mathrm{pN} 2$, and $138(22 \%)$ as $\mathrm{pN} 3$ according to the number of positive lymph nodes (Table 1 ).

Fifty-one percent of patients had lymph node ratio $(\mathrm{LNR})<0.20$ (lowrisk), 33\% had LNR of 0.21-0.65 (intermediate-risk), and 16\% of patients had LNR>0.65 (high-risk). Extracapsular invasion and/or perinodal fat infiltration were observed in $35 \%$ of patients. 
Table 1. Clinicopathologic characteristics of patients with node-positive breast cancer $(n=628)$

\begin{tabular}{|c|c|c|}
\hline Variables & $\mathbf{N}$ & $\%$ \\
\hline Age at diagnosis $\geq 50$ years & 408 & 65.0 \\
\hline Median (min-max) & $54(23-91)$ & \\
\hline Schooling $\geq 8$ years & 360 & 57.3 \\
\hline Race/ethnicity White & 348 & 55.4 \\
\hline Marital Status Living without a partner & 337 & 53.7 \\
\hline \multicolumn{3}{|l|}{ Clinical Staging } \\
\hline I & 42 & 6.7 \\
\hline$\| A$ & 150 & 23.9 \\
\hline IIB & 148 & 23.6 \\
\hline IIIA & 86 & 13.7 \\
\hline IIIB & 192 & 30.6 \\
\hline IIIC & 10 & 1.6 \\
\hline \multicolumn{3}{|l|}{ Histological type } \\
\hline Non-special type invasive carcinoma & 549 & 87.4 \\
\hline Lobular infiltrating carcinoma & 36 & 5.7 \\
\hline Other & 43 & 6.8 \\
\hline \multicolumn{3}{|l|}{ Histological grade } \\
\hline Grade 1 & 38 & 6.1 \\
\hline Grade 2 & 193 & 30.7 \\
\hline Grade 3 & 300 & 47.8 \\
\hline Estrogen receptor Positive & 480 & 76.4 \\
\hline Progesterone receptor Positive & 413 & 65.8 \\
\hline Her-2 Positive & 148 & 23.6 \\
\hline Surgery Mastectomy & 572 & 91.1 \\
\hline Trastuzumab Neo and/or adjuvant & 106 & 16.9 \\
\hline Chemotherapy Neo and/or adjuvant & 524 & 83.4 \\
\hline Radiotherapy Neo or adjuvant & 361 & 57.5 \\
\hline Hormone therapy Neo and/or adjuvant & 417 & 66.4 \\
\hline Tumor infiltration fat/perinodal extravasation & 222 & 35.4 \\
\hline Number of lymph nodes removed $\geq 10$ & 616 & 98.1 \\
\hline Median (min-max) & $19(6-77)$ & \\
\hline \multicolumn{3}{|l|}{ Number of positive lymph nodes } \\
\hline Median (min-max) & $4(1-49)$ & \\
\hline pN1 (1-3) & 304 & 48.4 \\
\hline pN2 (4-9) & 186 & 29.6 \\
\hline pN3 ( $\geq 10)$ & 138 & 22.0 \\
\hline \multicolumn{3}{|l|}{ Lymph node ratio } \\
\hline Median (min-max) & $0(0.02-1.00)$ & \\
\hline Low risk $(\leq 0.20)$ & 318 & 50.6 \\
\hline Intermediate risk (0.20-0.65) & 208 & 33.1 \\
\hline High risk (>0.65) & 102 & 16.2 \\
\hline
\end{tabular}

Missing values: Schooling (5; 0.8\%); Marital Status (1; 0.2\%); Histological grade $(97 ; 1.4 \%)$

pN: Number of positive lymph nodes
Table 2. Five-year disease-free survival and overall survival according to the number of positive lymph nodes and lymph node ratio

\begin{tabular}{|c|c|c|}
\hline \multirow[t]{2}{*}{ Variables } & \multicolumn{2}{|c|}{ 5-year disease free survival } \\
\hline & $\%$ (SD) & $\mathbf{p}$ \\
\hline \multicolumn{2}{|l|}{ Number of positive lymph nodes } & $<0.001$ \\
\hline pN1 (1-3) & $80.1(2.4)$ & \\
\hline pN2 (4-9) & $53.9(3.8)$ & \\
\hline pN3 ( $\geq 10)$ & $50.6(4.4)$ & \\
\hline Total & $65.8(2.0)$ & \\
\hline \multicolumn{2}{|l|}{ Lymph node ratio } & $<0.001$ \\
\hline Low risk $(\leq 0.20)$ & $79.2(2.4)$ & \\
\hline Intermediate risk (0.20-0.65) & $55.9(3.5)$ & \\
\hline High risk (>0.65) & $45.4(5.1)$ & \\
\hline Total & $65.9(2.0)$ & \\
\hline \multirow[t]{2}{*}{ Variables } & overall su & \\
\hline & $\%$ (SD) & $\mathbf{p}$ \\
\hline \multicolumn{2}{|l|}{ Number of positive lymph nodes } & $<0.001$ \\
\hline pN1 (1-3) & $84.3(2.2)$ & \\
\hline pN2 (4-9) & $69.4(3.5)$ & \\
\hline pN3 ( $\geq 10)$ & $62.3(4.3)$ & \\
\hline Total & $75.1(1.8)$ & \\
\hline \multicolumn{2}{|l|}{ Lymph node ratio } & $<0.001$ \\
\hline Low risk ( $\leq 0.20)$ & $83.4(2.2)$ & \\
\hline Intermediate risk (0.20-0.65) & $70.8(3.3)$ & \\
\hline High risk (>0.65) & $57.4(5.1)$ & \\
\hline Total & $75.1(1.8)$ & \\
\hline
\end{tabular}

Mastectomy was the treatment of choice in $91 \%$ of cases. Chemotherapy was administered in $83.4 \%$ of patients (neoadjuvant $=263$ patients [41.9\%]; adjuvant $=309$ patients [49.2\%]; both=48 patients [7.6\%] $66.4 \%$ received hormone therapy, and $17 \%$ of patients were treated with Trastuzumab (neoadjuvant=10 patients [1.6\%]; adjuvant=351 patients [55.9\%]) (Table 1). Neoadjuvant radiotherapy was performed in locally advanced tumors that did not respond to neoadjuvant chemotherapy and were inoperable before neoadjuvant radiotherapy.

The median follow-up was 58 months (range: 3-92 months). Diseasefree survival times of $\mathrm{pN} 1, \mathrm{pN} 2$, and $\mathrm{pN} 3$ patients were 53.8, 45.9, and 43.5 months, respectively $(\mathrm{p}<0.001)$. Overall survival times of $\mathrm{pN} 1, \mathrm{pN} 2$, and $\mathrm{pN} 3$ patients were 56.0, 52.3, and 50.0 months, respectively $(\mathrm{p}<0.001)$ (Table 2, Figure 1a, c).

The median disease-free survival times of low-, intermediate-, and high-risk LNR patients were 53.6, 46.3, and 41.5 months, respectively $(\mathrm{p}<0.001)$. In addition, the median overall survival times of low-, intermediate-, and high-risk LNR patients were 55.6, 52.9, and 48.8 months, respectively $(\mathrm{p}<0.001)$ (Table 2 , Figure $1 \mathrm{~b}, \mathrm{~d})$. 

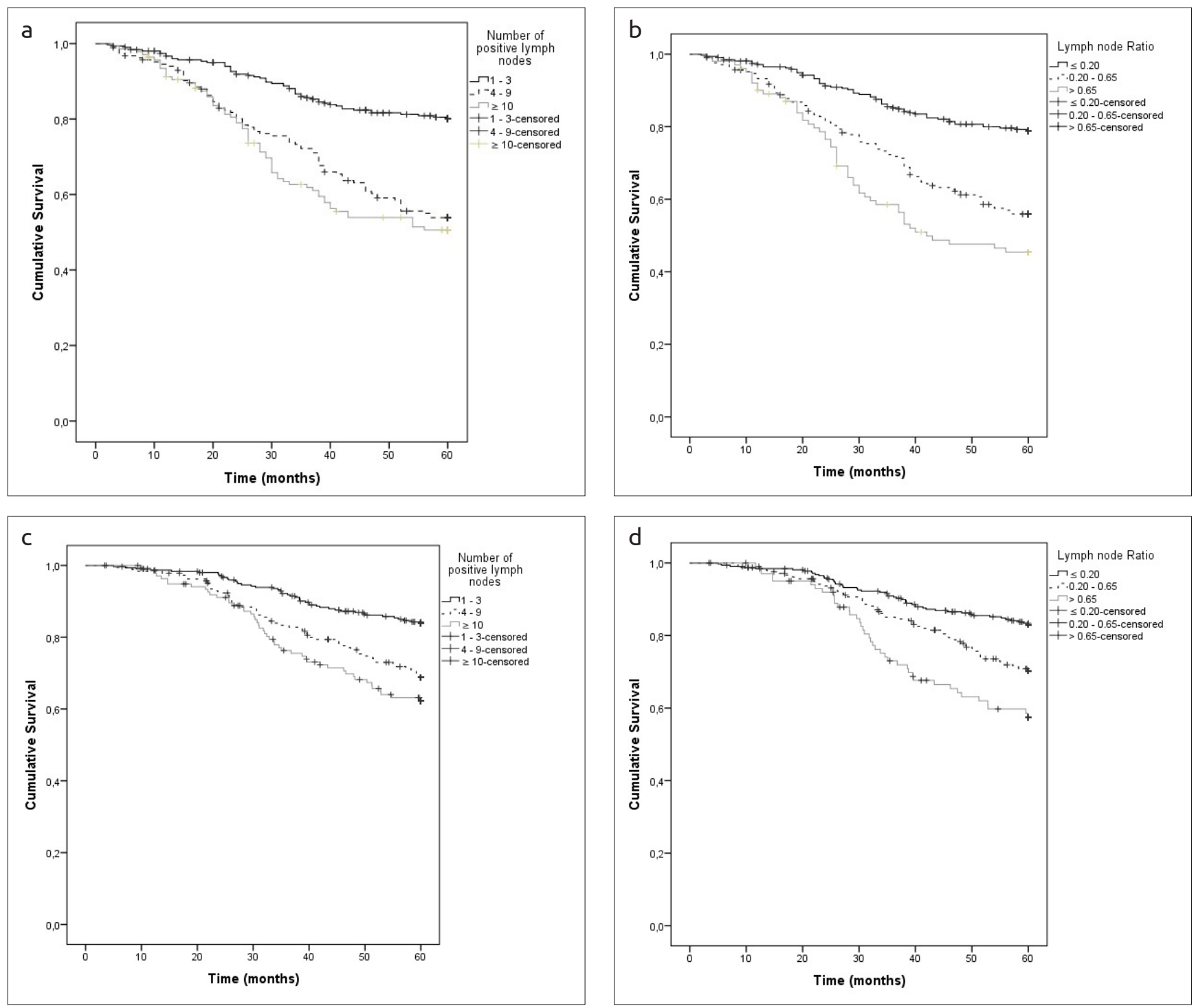

Figure 1. a-d. Kaplan-Meier Overall Survival estimates according to the number of positive lymph nodes (pN) and lymph node ratio (LNR) $(a, b)$. Kaplan-Meier Disease Free Survival estimates according to the number of positive lymph nodes (pN) and lymph node ratio (LNR) (c, d)

The univariate analysis of sociodemographic and clinical variables with risk of local recurrence and risk of death is presented in Table 3 and 4, respectively. The univariate and multiple Cox regression models for disease-free survival and overall survival are presented in Table 5.

In the DFS model, the adjusted five-year risk of breast cancer recurrence of $\mathrm{pN} 2$ and $\mathrm{pN} 3$ patients was 2.47 and 2.42 times greater, respectively, than that of $\mathrm{pN} 1$ patients $(\mathrm{p}<0.001)$. In addition, the fiveyear recurrence risk of intermediate- and high-risk LNR patients was 2.11 and 3.19 times greater, respectively, than that of low-risk LNR patients $(\mathrm{p}<0.001)($ Table 5).

In the OS model, the adjusted risk of death was greater in $\mathrm{pN} 2(\mathrm{HR}=2.17$, 95\% CI: $1.42-3.30)$ and $\mathrm{pN} 3(\mathrm{HR}=2.41,95 \% \mathrm{CI}: 1.53-3.78)$ patients than in $\mathrm{pN} 1$ patients. In addition, the risk of death of intermediate- and high-risk LNR patients was $1.70(\mathrm{p}=0.011)$ and $2.74(\mathrm{p}<0.001)$ times greater, respectively, than that of low-risk LNR patients (Table 5).

\section{Discussion and Conclusion}

This study evaluated a large cohort of women with breast cancer who were treated at a single oncology center. The results showed that the number of lymph nodes involved and lymph node ratio were useful predictors of risk of recurrence and risk of death in women with breast cancer.

Lymph node status has been widely regarded as an important prognostic factor in breast cancer and the TNM classification system remains the gold standard for staging the disease (3, 8, 9, 14, 15). Axillary lymph node status has been used for prognostic assessment and for guiding adjuvant, local or systemic treatment decisions (10, 16-20).

Some studies have shown that LNR improves the prognostication system compared with the use of $\mathrm{pN}$ alone (9). The importance of LNR has been demonstrated in colon, esophageal, gastric, pancreatic, bladder, vulvar, and cervical cancer (9), and there is now growing evidence of its prognostic value in breast cancer $(3,21,22)$.

Vinh-Hung et al. (9) investigated 1.829 women diagnosed with nodepositive breast cancer between 1980 and 2004 and identified LNR cutoff points that more accurately predicted the risk of breast cancer death and specific-survival rates, especially after 10 years. The authors showed that LNR predicts survival after breast cancer more accurately 
Table 3. Five-year disease-free survival and univariate analysis for the risk of recurrence in node-positive breast cancer

\begin{tabular}{|c|c|c|c|}
\hline Variables & 5-Year DFS \% (SD) & Hazard Ratio $(95 \% \mathrm{Cl})$ & $\mathbf{p}$ \\
\hline \multicolumn{4}{|l|}{ Age at diagnosis } \\
\hline$<50$ years & $61.5(3.3)$ & Reference & 0.106 \\
\hline$\geq 50$ years & $68.5(2.4)$ & $1.26(0.95-1.67)$ & \\
\hline \multicolumn{4}{|l|}{ Schooling } \\
\hline$<8$ years & $62.4(3.1)$ & $1.27(0.96-1.67$ & 0.094 \\
\hline$\geq 8$ years & $68.4(2.5)$ & Reference & \\
\hline \multicolumn{4}{|l|}{ Race/ethnicity } \\
\hline White & $68.7(2.6)$ & $0.81(0.61-1.07)$ & 0.132 \\
\hline Others & $62.5(3.0)$ & Reference & \\
\hline \multicolumn{4}{|l|}{ Marital Status } \\
\hline Living without a partner & $66.1(2.7)$ & $0.97(0.74-1.28)$ & 0.843 \\
\hline Living with a partner & $65.7(2.8)$ & Reference & \\
\hline \multicolumn{4}{|l|}{ Clinical Staging } \\
\hline$\geq I I B$ & $58.4(2.4)$ & $2.85(1.95-4.18)$ & $<0.001$ \\
\hline$<I I B$ & $83.0(2.8)$ & Reference & \\
\hline \multicolumn{4}{|l|}{ Histological type } \\
\hline Non-special type invasive carcinoma & $64.5(2.1)$ & $1.68(1.03-2.72)$ & 0.037 \\
\hline Others & $75.7(5.0)$ & Reference & \\
\hline \multicolumn{4}{|l|}{ Histologic grade } \\
\hline Low & $77.5(2.8)$ & Reference & $<0.001$ \\
\hline High & $56.1(3.0)$ & $2.33(1.67-3.23)$ & \\
\hline \multicolumn{4}{|l|}{ Estrogen receptor } \\
\hline Negative & $48.7(4.3)$ & $2.22(1.66-2.97)$ & $<0.001$ \\
\hline Positive & $71.1(2.1)$ & Reference & \\
\hline \multicolumn{4}{|l|}{ Progesterone receptor } \\
\hline Negative & $53.6(3.5)$ & $2.01(1.52-2.65)$ & $<0.001$ \\
\hline Positive & $72.3(2.3)$ & Reference & \\
\hline \multicolumn{4}{|l|}{ Her-2 } \\
\hline Negative & $69.0(2.2)$ & Reference & 0.003 \\
\hline Positive & $56.6(4.1)$ & $1.56(1.16-2.10)$ & \\
\hline \multicolumn{4}{|l|}{ Surgery } \\
\hline Mastectomy & $63.9(2.1)$ & $3.20(1.50-6.80)$ & 0.003 \\
\hline Conservative & $86.8(4.6)$ & Reference & \\
\hline \multicolumn{4}{|l|}{ Trastuzumab } \\
\hline Yes & $61.2(4.7)$ & $1.26(0.89-1.77)$ & 0.192 \\
\hline No & $66.9(2.1)$ & Reference & \\
\hline \multicolumn{4}{|l|}{ Chemotherapy } \\
\hline Yes & $64.1(2.1)$ & $1.64(1.06-2.56)$ & 0.028 \\
\hline No & $76.3(4.6)$ & Reference & \\
\hline \multicolumn{4}{|l|}{ Radiotherapy } \\
\hline Yes & $67.1(2.5)$ & $0.87(0.66-1.15)$ & 0.319 \\
\hline No & $64.3(3.1)$ & Reference & \\
\hline \multicolumn{4}{|l|}{ Hormone therapy } \\
\hline Yes & $74.0(2.2)$ & $0.39(0.30-0.52)$ & $<0.001$ \\
\hline No & $48.9(3.7)$ & Reference & \\
\hline \multicolumn{4}{|c|}{ Tumor infiltration fat/perinodal extravasation } \\
\hline Yes & $63.0(3.3)$ & $1.21(0.92-1.61)$ & 0.180 \\
\hline No & $67.5(2.4)$ & Reference & \\
\hline \multicolumn{4}{|l|}{ Number of Lymph nodes removed } \\
\hline$<10$ & $72.7(13.4)$ & Reference & \\
\hline$\geq 10$ & $65.8(2.0)$ & $1.46(0.47-4.57)$ & 0.516 \\
\hline
\end{tabular}


Table 4. Five-year overall survival and univariate analysis for the risk of death in node-positive breast cancer

\begin{tabular}{|c|c|c|c|}
\hline Variables & 5-Year OS \% (SD) & Hazard Ratio $(95 \% \mathrm{Cl})$ & $\mathbf{P}$ \\
\hline \multicolumn{4}{|l|}{ Age at diagnosis } \\
\hline$<50$ years & $75.3(3.0)$ & $0.950(0.68-1.33)$ & 0.763 \\
\hline$\geq 50$ years & $75.0(2.2)$ & Reference & \\
\hline \multicolumn{4}{|l|}{ Schooling } \\
\hline$<8$ years & $72.7(2.9)$ & $1.15(0.83-1.59)$ & 0.391 \\
\hline$\geq 8$ years & $76.7(2.3)$ & Reference & \\
\hline \multicolumn{4}{|l|}{ Race/ethnicity } \\
\hline White & $77.9(2.3)$ & $0.75(0.54-1.03)$ & 0.079 \\
\hline Others & $71.7(2.8)$ & Reference & \\
\hline \multicolumn{4}{|l|}{ Marital Status } \\
\hline Living without a partner & $74.4(2.5)$ & $1.13(0.81-1.56)$ & 0.470 \\
\hline Living with a partner & $76.1(2.6)$ & Reference & \\
\hline \multicolumn{4}{|l|}{ Clinical Staging } \\
\hline$\geq \mathrm{II} B$ & $68.4(2.3)$ & $3.41(2.10-5.52)$ & $<0.001$ \\
\hline$<I I B$ & $90,1(2.2)$ & Reference & \\
\hline \multicolumn{4}{|l|}{ Histological type } \\
\hline Non-special type invasive carcinoma & 73.9 (1.9) & $1.80(1.00-3.26)$ & 0.049 \\
\hline Others & $83.5(4.4)$ & Reference & \\
\hline \multicolumn{4}{|l|}{ Histologic grade } \\
\hline Low & $87.7(2.2)$ & Reference & $<0.001$ \\
\hline High & $63.2(2.9)$ & $3.32(2.19-5.01)$ & \\
\hline \multicolumn{4}{|l|}{ Estrogen receptor } \\
\hline Negative & $55.4(4.4)$ & $3.01(2.17-4.19)$ & $<0.001$ \\
\hline Positive & $80.7(1.8)$ & Reference & \\
\hline \multicolumn{4}{|l|}{ Progesterone receptor } \\
\hline Negative & $63.9(3.4)$ & $2.20(1.60-3.04)$ & $<0.001$ \\
\hline Positive & $80.6(2.0)$ & Reference & \\
\hline \multicolumn{4}{|l|}{ Her-2 } \\
\hline Negative & $77.7(2.0)$ & Reference & 0.006 \\
\hline Positive & $66.6(4.0)$ & $1.62(1.15-2.28)$ & \\
\hline \multicolumn{4}{|l|}{ Surgery } \\
\hline Mastectomy & $73.4(1.9)$ & $4.10(1.52-11.09)$ & 0.005 \\
\hline Conservative & $92.3(3.7)$ & Reference & \\
\hline \multicolumn{4}{|l|}{ Trastuzumab } \\
\hline Yes & $71.6(4.5)$ & $1.18(0.79-1.78)$ & 0.409 \\
\hline No & $75.8(1.9)$ & Reference & \\
\hline \multicolumn{4}{|l|}{ Chemotherapy } \\
\hline Yes & $73.3(2.0)$ & $1.78(1.02-3.09)$ & 0.040 \\
\hline No & $85.4(3.8)$ & Reference & \\
\hline \multicolumn{4}{|l|}{ Radiotherapy } \\
\hline Yes & $78.1(2.2))$ & $0.68(0.49-0.94)$ & \\
\hline No & $70.8(2.9)$ & Reference & 0.020 \\
\hline \multicolumn{4}{|l|}{ Hormone therapy } \\
\hline Yes & $84.4(1.8)$ & $0.27(0.19-0.37)$ & \\
\hline No & $55.5(3.6)$ & Reference & $<0.001$ \\
\hline \multicolumn{4}{|c|}{ Tumor infiltration fat/perinodal extravasation } \\
\hline Yes & $70.6(3.1)$ & $1.34(0.97-1.86)$ & 0.074 \\
\hline No & $77.6(2.1)$ & Reference & \\
\hline \multicolumn{4}{|l|}{ Number of Lymph nodes removed } \\
\hline$<10$ & $90.9(8.7)$ & Reference & 0.542 \\
\hline$\geq 10$ & $74.8(1.8)$ & $1.54(0.38-6.23)$ & \\
\hline
\end{tabular}


Table 5. Cox regression model (crude and adjusted) for risk of recurrence and death

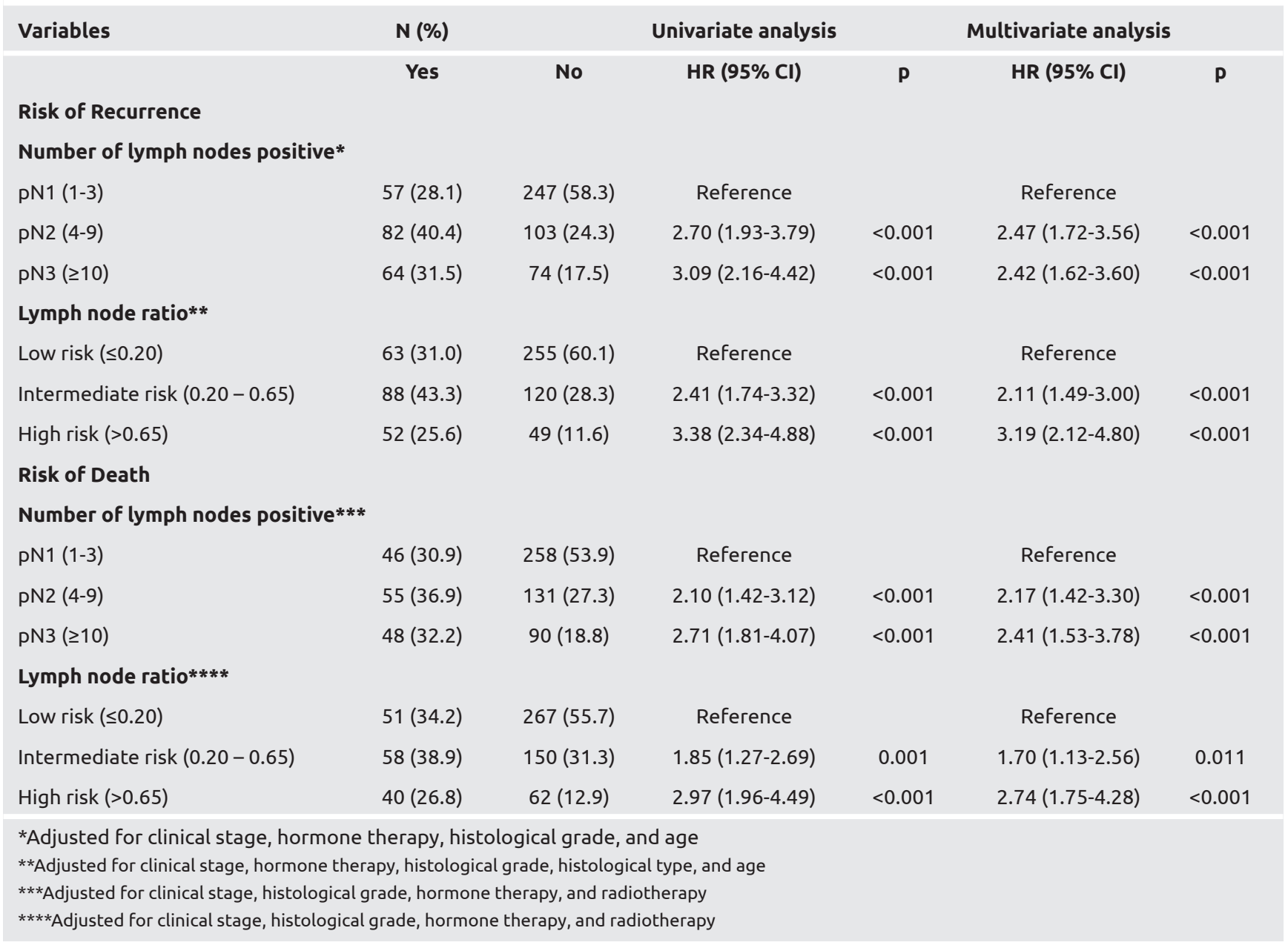

than the $\mathrm{pN}$ classification of the TNM staging system and suggested that LNR should be considered as an alternative or improvement to $\mathrm{pN}$ staging. In that study, the breast cancer-specific survival rates at 10 years for patients with $\mathrm{LNR} \leq 0.20, \mathrm{LNR}=0.21-0.65$, and $\mathrm{LNR}>0.65$ were $75 \%, 63 \%$, and $40 \%$, respectively. In addition, the adjusted hazard ratio of breast cancer mortality risk was 1.78 (95\% CI: 1.46-2.18) for patients in the intermediate LNR risk group ( $\mathrm{LNR}=0.21-0.65$ ) and 3.21 (95\% CI: 2.54-4.06) for patients in the high LNR $(>0.65)$ risk group compared with patients in the low LNR risk group. Similarly, Kim et al. (22) analyzed 3.477 patients with T1-T2 node-positive breast cancer and demonstrated the clinical relevance of LNR, which was characterized by cutoff points similar to those reported by VinhHung et al. (9). In addition, using another cut-off, Kuru et al. (23) found that $\mathrm{P} / \mathrm{N}$ ratio $>0.25$ was associated with a high risk of death (HR 3.8, CI 2.74 -5.50).

More recently, following the results of randomized clinical trials such as the International Breast Cancer Study Group 23-01 (IBCSG 23-01) (24) and ACOSOG Z0011 (4, 5), the role of LNR has been called into question. Nevertheless, even in patients that do not meet the criteria used in these two studies (patients with early disease and, in general, who receive adjuvant treatment such as local radiotherapy), LNR has superior prognostic value compared with $\mathrm{pN}$. Thus, the role of LNR
Contrary to other studies $(1,7,11,22)$, there were no significant differences in disease-free survival $(\mathrm{HR}=1.21,95 \% \mathrm{CI}$ : 0.92-1.61; $\mathrm{p}=0.180)$ and overall survival $(\mathrm{HR}=1.34,95 \% \mathrm{CI}: 0.97-1.86$; $\mathrm{p}=0.074$ ) between patients with and without extracapsular invasion and perinodal fat infiltration.

Some limitations of the current study should be highlighted. The data analyzed here are from a pre-ACOSOG Z0011 cohort series of patients who were diagnosed and treated between 2008 and 2009, when patients with positive lymph nodes on SLNB were treated with axillary dissection. In addition, all cases were collected from a single cancer center, which may adversely affect external validity because cases may not be representative of the general population. Nevertheless, some strengths of the study should be noted. This is a single-center study and the same diagnostic and treatment procedures were used for all patients during the study period, strengthening the internal validity of the data. The histopathological data were examined by a team of experienced pathologists specialized in breast cancer, improving the reliability of results. In addition, histopathological variables were extracted directly from electronic charts minimizing information bias. Another strength of the study is the relatively short inclusion period (two years), which prevented novel technologies and changes in treatment choice from affecting prognosis. Lastly, the long follow-up time enabled the accurate identification of the outcomes analyzed. 
The era of personalized molecular medicine and genomics-based tumor profiling is paving the way to precision medicine $(26,27)$. However, this high-cost approach to disease treatment and prevention is far from the reality of most patients in developing countries like Brazil, especially those relying on public health services. Nowadays, Oncotype DX testing and biomarkers (Her-2, RE, RP) are important players in clinical decision-making. They are expensive; hence, some poor countries may have uncertainties in making them available for systematic clinical use. In this context, data such as $\mathrm{pN}$ and LNR are important and low-cost prognostic factors. Thus, we believe that extracting additional useful information from histopathological reports at no extra costs, such as lymph node ratio, may benefit a significant number of patients and therefore should be implemented as prognostic factors of node-positive breast cancer.

In women with node-positive breast cancer, the number of positive lymph nodes $(\mathrm{pN})$ and lymph node ratio (LNR) are important prognostic factors of disease-free survival and overall survival.

Ethics Committee Approval: Ethics committee approval was received for this study from the Ethics Committee of Instituto Nacional de Câncer (128/11).

Informed Consent: Informed consent was not taken due to retrospective design of the study.

Peer-review: Externally peer-reviewed.

Author Contributions: Concept - F.T., L.C.S.T.; Design - F.T., A.B.; Supervision - L.C.S.T., A.B.; Data Collection and/or Processing - F.T., K.A., S.S.A.; Analysis and/or Interpretation - F.T., L.C.S.T., A.B., M.A.B.; Literature Search - F.T., M.A.B.; Writing Manuscript - F.T., L.C.S.T., A.B.; Critical Review L.C.S.T., A.B.

Conflict of Interest: The authors have no conflicts of interest to declare.

Financial Disclosure: The authors declared that this study has received no financial support.

\section{References}

1. Nottegar A, Veronese N, Senthil M, Roumen RM, Stubbs B, Choi AH, Verheuvel NC, Solmi M, Pea A, Capelli P, Fassan M, Sergi G, Manzato E, Maruzzo M, Bagante F, Koç M, Eryilmaz MA, Bria E, Carbognin L, Bonetti F, Barbareschi M, Luchini C. Extra-nodal extension of sentinel lymph node metastasis is a marker of poor prognosis in breast cancer patients: A systematic review and an exploratory meta-analysis. Eur J Surg Oncol 2016; 42: 919-925. (PMID: 27005805) [CrossRef]

2. Instituto Nacional de Câncer José Gomes de Alencar. Estimates 2016: Cancer Incidence in Brazil. Rio de Janeiro. Available from: URL: http:// www.inca.gov.br/estimativa/2016/INCA;2 016.

3. Hong R, Dai Z, Zhu W, Xu B. Association between lymph node ratio and disease specific survival in breast cancer patients with one or two positive lymph nodes stratified by different local treatment modalities. PLoS One 2015; 29: e0138908. (PMID: 26513258) [CrossRef]

4. Giuliano AE, Hunt KK, Ballman KV, Beitsch PD, Whitworth PW, Blumencranz PW, Leitch AM, Saha S, McCall LM, Morrow M. Axillary dissection vs no axillary dissection in women with invasive breast cancer and sentinel node metastasis: a randomized clinical trial. JAMA 2011; 305: 569-575. (PMID: 21304082) [CrossRef]

5. Giuliano AE, Ballman K, McCall L, Beitsch P, Whitworth PW, Blumencranz P, Leitch AM, Saha S, Morrow M, Hunt KK. Locoregional recurrence after sentinel lymph node dissection with or without axillary dissection in patients with sentinel lymph node metastases: long-term follow-up from the American College of Surgeons Oncology Group (Alliance) ACOSOG Z0011 Randomized Trial. Ann Surg 2016 ; 264: 413420. (PMID: 27513155) [CrossRef]

6. Neri A, Marrelli D, Roviello F, De Stefano A, Guarnieri A, Pallucca E, Pinto E. Prognostic value of extracapsular extension of axillary lymph node metastases in T1 to T3 breast cancer. Ann Surg Oncol 2005; 12: 246-253. (PMID: 15827817) [CrossRef]

7. Unal D, Oguz A, Tasdemir A. Rate of metastasis in examined lymph nodes as a predictor of extracapsular extension in patients with axillary node-positive breast cancer. J Nippon Med Sch 2014; 81: 372-377. (PMID: 25744480) [CrossRef]

8. Danko ME, Bennett KM, Zhai J, Marks JR, Olson JA Jr. Improved staging in node-positive breast cancer patients using lymph node ratio: results in 1,788 patients with long-term follow-up. J Am Coll Surg 2010; 210: 797-805. (PMID: 20421053) [CrossRef]

9. Vinh-Hung V, Verkooijen HM, Fioretta G, Neyroud-Caspar I, Rapiti E, Vlastos G, Deglise C, Usel M, Lutz JM, Bouchardy C. Lymph node ratio as an alternative to $\mathrm{pN}$ staging in node-positive breast cancer. J Clin Oncol 2009; 27: 1062-1068. (PMID: 19164210) [CrossRef]

10. Gooch J, King TA, Eaton A, Dengel L, Stempel M, Corben AD, Morrow $M$. The extent of extracapsular extension may influence the need for axillary lymph node dissection in patients with T1-T2 breast cancer. Ann Surg Oncol 2014; 21: 2897-2903. (PMID: 24777858) [CrossRef]

11. Fisher BJ, Perera FE, Cooke AL, Opeitum A, Dar AR, Venkatesan VM, Stitt L, Radwan JS. Extracapsular axillary node extension in patients receiving adjuvant systemic therapy: an indication for radiotherapy? Int J Radiat Oncol Biol Phys 1997; 38: 551-559. (PMID: 9231679) [CrossRef]

12. Rose BS, Jiang W, Punglia RS. Effect of lymph node metastasis size on breast cancer-specific and overall survival in women with node-positive breast cancer. Breast Cancer Res Treat 2015; 152: 209-216. (PMID: 26041688) [CrossRef]

13. AJCC staging system 7 th Edition Staging Posters, American Cancer Society. 2009.

14. Singletary SE, Allred C, Ashley P, Bassett LW, Berry D, Bland KI, Borgen PI, Clark G, Edge SB, Hayes DF, Hughes LL, Hutter RV, Morrow M, Page DL, Recht A, Theriault RL, Thor A, Weaver DL, Wieand HS, Greene FL. Revision of the American Joint Committee on Cancer staging system for breast cancer. J Clin Oncol 2002; 20: 3628-3636. (PMID: 12202663) [CrossRef]

15. Chagpar AB, Camp RL, Rimm DL. Lymph node ratio should be considered for incorporation into staging for breast cancer. Ann Surg Oncol 2011; 18: 3143-3148. (PMID: 21847696) [CrossRef]

16. Verheuvel NC, Ooms HW, Tjan-Heijnen VC, Roumen RM, Voogd AC. Predictors for extensive nodal involvement in breast cancer patients with axillary lymph node metastases. Breast 2016; 27: 175-181. (PMID: 27123958) [CrossRef]

17. Rao R, Euhus D, Mayo HG, Balch C. Axillary node interventions in breast cancer: a systematic review. JAMA 2013; 310: 1385-1394. (PMID: 24084924) [CrossRef]

18. Tsai J, Bertoni D, Hernandez-Boussard T, Telli ML, Wapnir IL. Lymph node ratio analysis after neoadjuvant chemotherapy is prognostic in hormone receptor-positive and triple-negative breast cancer. Ann Surg Oncol 2016; 23: 3310-3316. (PMID: 27401442) [CrossRef]

19. Harris EE, Freilich J, Lin HY, Chuong M, Acs G. The impact of the size of nodal metastases on recurrence risk in breast cancer patients with 1-3 positive axillary nodes after mastectomy. Int J Radiat Oncol Biol Phys 2013; 85: 609-614. (PMID: 22867892) [CrossRef]

20. Chagpar AB, Camp RL, Rimm DL. Lymph node ratio should be considered for incorporation into staging for breast cancer. Ann Surg Oncol 2011; 18: 3143-3148. (PMID: 21847696) [CrossRef]

21. Martin FT, O'Fearraigh C, Hanley C, Curran C, Sweeney KJ, Kerin MJ. The prognostic significance of nodal ratio on breast cancer recurrence and its potential for incorporation in a new prognostic index. Breast J 2013; 19: 388-393. (PMID: 23721403) [CrossRef] 


\section{Eur J Breast Health 2019; 15(2): 76-84}

22. Kim SI, Cho SH, Lee JS, Moon HG, Noh WC, Youn HJ, Ko BK, Park BW. Clinical relevance of lymph node ratio in breast cancer patients with one to three positive lymph nodes. Br J Cancer 2013; 109: 1165-1171. (PMID: 23942073)

23. Kuru B. Prognostic significance of total number of nodes removed, negative nodes removed, and ratio of positive nodes to removed nodes in node positive breast carcinoma. Eur J Surg Oncol 2006; 32: 1082-1088. (PMID: 16887320) [CrossRef]

24. Galimberti V, Cole BF, Zurrida S, Viale G, Luini A, Veronesi P, Baratella P, Chifu C, Sargenti M, Intra M, Gentilini O, Mastropasqua MG, Mazzarol G, Massarut S, Garbay JR, Zgajnar J, Galatius H, Recalcati A, Littlejohn D, Bamert M, Colleoni M, Price KN, Regan MM, Goldhirsch A, Coates AS, Gelber RD, Veronesi U; International Breast Cancer Study Group Trial 23-01 investigators. International Breast Cancer Study Group Trial 23-01 investigators. Axillary dissection versus no axillary dis- section in patients with sentinel-node micrometastases (IBCSG 23-01): a phase 3 randomised controlled trial. Lancet Oncol 2013; 14: 297-305. (PMID: 23491275) [CrossRef]

25. Wu SG, Li Q, Zhou J, Sun JY, Li FY, Lin Q, Lin HX, Gaun XX, He ZY. Using the lymph node ratio to evaluate the prognosis of stage II/III breast cancer patients who received neoadjuvant chemotherapy and mastectomy. Cancer Res Treat 2015; 47: 757-764. (PMID: 25672578) [CrossRef]

26. Araujo LH, Krook, Roychowdhury S. Impact of genomic sequencing on precision medicine for clinical oncology. Expert Rev Precis Med Drug Dev 2016; 1: 255-265. [CrossRef]

27. Exner R, Bago-Horvath Z, Bartsch R, Mittlboeck M, Retèl VP, Fitzal F, Rudas M, Singer C, Pfeiler G, Gnant M, Jakesz R, Dubsky P. The multigene signature mammaprint impacts on multidisciplinary team decisions in ER+, HER2- early breast cancer. Br J Cancer 2014; 26: 837-842. (PMID: 25003667) [CrossRef] 